\section{Kidney \\ Blood Pressure Research}

Kidney Blood Press Res 2015;40:490-499

\title{
Inhibition of Phosphate-Induced Vascular Smooth Muscle Cell Osteo-/Chondrogenic Signaling and Calcification by Bafilomycin A1 and Methylamine
}

\author{
Ioana Alesutan Katharina Musculus Tatsiana Castor Kousi Alzoubi \\ Jakob Voelkl Florian Lang \\ Department of Physiology, University of Tübingen, Gmelinstr.5, 72076, Tübingen, Germany
}

\section{Key Words}

Calcification - Senescence • Vesicular pH $\cdot \mathrm{H}^{+}$pump • Phosphate - TGFB1 • NFAT5 • Alkaline phosphatase $\cdot$ Osteoinductive signaling

\begin{abstract}
Background/Aims: Excessive phosphate concentrations trigger vascular calcification, an active process promoted by osteoinduction of vascular smooth muscle cells (VSMCs) with increased expression and activity of transcription factor RUNX2 (Core-binding factor $\alpha 1$, CBFA1), alkaline phosphatase (ALPL), TGFß1, transcription factor NFAT5, and NFAT5-sensitive transcription factor SOX9. The osteoinductive signaling and vascular calcification of hyperphosphatemic klothohypomorphic mice could be reversed by treatment with $\mathrm{NH}_{4} \mathrm{Cl}$, effects involving decrease of TGFB1 and inhibition of NFAT5-dependent osteoinductive signaling. Known effects of $\mathrm{NH}_{4} \mathrm{Cl}$ include alkalinization of acidic cellular compartments. The present study explored whether osteo-/ chondrogenic signaling could be influenced by alkalinization of acidic cellular compartments following inhibition of the vacuolar $\mathrm{H}^{+}$ATPase with bafilomycin $\mathrm{A} 1$ or following dissipation of the $\mathrm{pH}$ gradient across the membranes of acidic cellular compartments with methylamine. Methods: Primary human aortic smooth muscle cells (HAoSMCs) were treated with high phosphate to trigger osteo-/chondrogenic signaling and calcification in the absence or presence of bafilomycin A1 or methylamine. Calcium content was determined using a QuantiChrom Calcium assay, ALP activity by a colorimetric assay and transcript levels by quantitative RTPCR. Results: High phosphate increased significantly the calcium deposition, CBFA1 and ALPL mRNA expression as well as alkaline phosphatase activity in HAoSMCs, all effects ameliorated by both, bafilomycin A1 and methylamine. High phosphate further significantly up-regulated the mRNA levels of TGFB1, NFAT5 and SOX9, effects significantly blunted by additional treatment with bafilomycin A1 or methylamine. Treatment of HAoSMCs with human TGFB1 protein or high phosphate up-regulated NFAT5, SOX9, CBFA1 and ALPL mRNA expression to




\section{Kidney Blood Pressure Research}

Kidney Blood Press Res 2015;40:490-499

DOI: 10.1159/000368524

Published online: September 30, 2015

(C) 2015 The Author(s). Published by S. Karger AG, Base

www.karger.com/kbr

similarly high levels which could not be further increased by combined treatment with high phosphate and TGFß1. Bafilomycin A1 failed to reverse the osteo-/chondrogenic signaling triggered by high phosphate together with TGFB1. Conclusions: Inhibition of the vacuolar $\mathrm{H}^{+}$ ATPase or dissipation of the $\mathrm{pH}$ gradient across the membranes of acidic cellular compartments both disrupt osteo-/chondrogenic signaling and calcium deposition in VSMCs, observations supporting the hypothesis that vascular calcification requires acidic cellular compartments.

(C) 2015 The Author(s)

Published by S. Karger AG, Basel

\section{Introduction}

Vascular calcification, a hallmark of aging [1-4], is promoted by hyperphosphatemia [5], which accelerates aging and increases cardiovascular risk [6]. Excessive plasma phosphate concentrations with subsequent mineral bone disorder (MBD) and vascular calcification are particularly decisive for the mortality of patients with chronic kidney disease (CKD) [4, 7].

Vascular calcification is, however, not simply due to precipitation of $\mathrm{CaHPO}_{4}$ salts, but results from a complex active process [8] involving reprogramming of vascular smooth muscle cells (VSMCs) into osteo-/chondrogenic phenotypes [9]. The osteo-/chondrogenic reprogramming of VSMCs is triggered by increased extracellular phosphate concentrations [5]. Signaling involved in osteo-/chondrogenic differentiation of VSMCs include up-regulation of CBFA1/ RUNX2 (Core-binding factor $\alpha 1$ ), an osteogenic transcription factor [10] orchestrating the transformation of VSMCs into osteoblast-like cells [11-13]. CBFA1-dependent genes include the alkaline phosphatase [12,14-16], which degrades the calcification inhibitor pyrophosphate [10, 17]. CBFA1 expression is up-regulated by the TGFß1-sensitive [18] transcription factor NFAT5 (nuclear factor of activated T-cells 5) [19], an effect involving the transcription factor SOX9 [19]. SOX9 is up-regulated in uremia [20] and participates in the stimulation of chondrogenic gene expression in VSMCs [21]. TGFß1 thus stimulates osteogenic signaling [22-25]. Vascular osteoinduction is closely associated with VSMC senescence [26], which parallels vascular aging and injury [27].

A recent study disclosed an inhibitory effect of $\mathrm{NH}_{4} \mathrm{Cl}$ on osteogenic signaling and vascular calcification [28]. $\mathrm{NH}_{4}{ }^{+}$may dissociate thus yielding $\mathrm{NH}_{3}$, which easily crosses membranes, thus entering cells and cellular compartments. In acidic compartments, $\mathrm{NH}_{3}$ binds $\mathrm{H}^{+}$and is thus trapped as $\mathrm{NH}_{4}^{+}$[29]. As a result, $\mathrm{NH}_{4} \mathrm{Cl}$ alkalinizes acidic cellular compartments, which is known to prevent maturation of several proteins including TGFß1 [30]. It was thus hypothesized that $\mathrm{NH}_{4}{ }^{+}$is effective by alkalinizing acidic cellular compartments. However, at least in theory, $\mathrm{NH}_{4} \mathrm{Cl}$ may inhibit calcification by triggering acidosis [31-33]. Alternative methods leading to alkalinisation of acidic intracellular compartments include inhibition of the vacuolar $\mathrm{H}^{+}$ATPase with bafilomycin A1 [34] and the dissipation of the $\mathrm{pH}$ gradient across the vacuolar membrane with methylamine [35].

The present study explored the effect of bafilomycin A1 and of methylamine on osteo-/ chondrogenic signaling and calcification induced by high phosphate in primary human aortic smooth muscle cells.

\section{Materials and Methods}

\section{Cell culture of HAoSMCs}

Primary human aortic smooth muscle cells (Invitrogen, Life Technologies) were routinely cultured in Waymouth's MB 752/1 medium and Ham's F-12 nutrient mixture (1:1, Gibco, Life Technologies) supplemented with $10 \%$ FBS (Gibco, Life Technologies) and $100 \mathrm{U} / \mathrm{ml}$ penicillin and $100 \mu \mathrm{g} / \mathrm{ml}$ streptomycin (Gibco, Life Technologies). HAoSMCs were grown to confluency and used in all experiments from passages 4 to 10. Where indicated, HAoSMCs were treated with $2 \mathrm{mM} \beta$-glycerophosphate (Sigma-Aldrich), with 3 mM sodium phosphate buffer, pH 7.4 (Sigma-Aldrich), with $500 \mathrm{nM}$ bafilomycin A1 (Sigma-Aldrich, solved in 


\section{Kidney \\ Blood Pressure Research}

Kidney Blood Press Res 2015;40:490-499

\begin{tabular}{l|l}
\hline DOI: 10.1159/000368524 & (C) 2015 The Author(s). Published by S. Karger AG, Basel
\end{tabular}

Published online: September 30, 2015 www.karger.com/kbr

DMSO), with $1 \mathrm{mM}$ methylamine (Sigma-Aldrich) and/or with $10 \mathrm{ng} / \mathrm{ml}$ human TGF $\beta 1$ (R\&D Systems, solved in $4 \mathrm{mM} \mathrm{HCl}$ solution containing $1 \mathrm{mg} / \mathrm{ml} \mathrm{BSA}$ ). Equal amounts of vehicle were used as control.

Quantitative RT-PCR

HAoSMCs were washed with PBS and total RNA was isolated using Trifast Reagent (Peqlab) according to the manufacturer's instructions. Reverse transcription of $2 \mu \mathrm{g}$ RNA was performed using oligo(dT) ${ }_{12-18}$ primers (Invitrogen) and SuperScriptIII Reverse Transcriptase (Invitrogen). Quantitative real-time PCR was performed with the iCycler $\mathrm{iQ}^{\mathrm{TM}}$ Real-Time PCR Detection System (Bio-Rad Laboratories) and $\mathrm{iQ}^{\mathrm{TM}}$ Sybr Green Supermix (Bio-Rad Laboratories) according to the manufacturer's instructions. The following human primers were used $\left(5^{\prime} \rightarrow 3^{\prime}\right.$ orientation):

TN alkaline phosphatase fw: GGGACTGGTACTCAGACAACG;
TN alkaline phosphatase rev: GTAGGCGATGTCCTTACAGCC;
CBFA1 fw: GCCTTCCACTCTCAGTAAGAAGA;
CBFA1 rev: GCCTGGGGTCTGAAAAAGGG;
GAPDH fw: GAGTCAACGGATTTGGTCGT;
GAPDH rev: GACAAGCTTCCCGTTCTCAG;
NFAT5 fw: GGGTCAAACGACGAGATTGTG;
NFAT5 rev: GTCCGTGGTAAGCTGAGAAAG;
SOX9 fw: AGCGAACGCACATCAAGAC;
SOX9 rev: CTGTAGGCGATCTGTTGGGG;
TGFB1 fw: CAATTCCTGGCGATACCTCAG;
TGFB1 rev: GCACAACTCCGGTGACATCAA.

The specificity of the PCR products was confirmed by analysis of the melting curves. All PCRs were performed in duplicate and relative mRNA fold changes were calculated by the $2^{-\Delta \Delta C t}$ method using GAPDH as internal reference.

\section{Calcium content}

HAoSMCs were treated for 14 days with 3 mM sodium phosphate buffer as calcification media. Fresh media with agents were added every 2-3 days. After the incubation period, HAoSMCs were decalcified for 24 hours at $4^{\circ} \mathrm{C}$ in $0.6 \mathrm{M} \mathrm{HCl}$. The calcium content was determined colorimetrically using a QuantiChrom Calcium assay kit (BioAssay Systems) according to the manufacturer's protocol. After washing with PBS, HAoSMCs were lysed with $0.1 \mathrm{M} \mathrm{NaOH} / 0.1 \%$ SDS. Calcium content was normalized to total protein concentration as assessed by the Bradford assay (Bio-Rad Laboratories).

Alkaline phosphatase (ALP) activity assay

For determination of cellular ALP activity, HAoSMCs were treated for 7 days. Fresh media with agents were added every 2-3 days. After the incubation period, HAoSMCs were washed with PBS and assayed for ALP activity using the ALP colorimetric assay kit (Abcam) according to the manufacturer's protocol. ALP activity was normalized to total protein concentration as assessed by the Bradford assay (Bio-Rad Laboratories).

\section{Statistics}

Data are provided as arithmetic means \pm SEM, $n$ represents the number of experiments. Normality was tested with Shapiro-Wilk test. Statistical testing was performed by one-way Anova followed by Tukey-test for homoscedastic data or Games-Howell test for heteroscedastic data. Non-normal data was tested by the Steel-Dwass method. Results with $p<0.05$ were considered statistically significant.

\section{Results}

In order to explore whether vacuolar $\mathrm{pH}$ impacts on vascular calcification, experiments have been performed in primary human aortic smooth muscle cells (HAoSMCs) treated with high phosphate with or without inhibition of the vacuolar $\mathrm{H}^{+}$pump with bafilomycin 


\section{Kidney \\ Blood Pressure Research}

Kidney Blood Press Res 2015;40:490-499

DOI: $10.1159 / 000368524$

Published online: September 30, 2015

(C) 2015 The Author(s). Published by S. Karger AG, Base

www.karger.com/kbr

493

Fig. 1. Bafilomycin $A 1$ and methylamine interfere with phosphate-induced calcification in primary human aortic smooth muscle cells. Arithmetic means \pm SEM ( $n=8$; $\mu \mathrm{g} / \mathrm{mg}$ protein) of calcium content in HAoSMCs after 14 days of treatment with control (white bar, Ctr), with 3 $\mathrm{mM}$ sodium phosphate alone (black bar, Pi), with $3 \mathrm{mM}$ sodium phosphate and $500 \mathrm{nM}$ bafilomycin A1 (light grey bar, Pi+BafA1) or with $3 \mathrm{mM}$ sodium phosphate and 1 $\mathrm{mM}$ methylamine (dark grey bar, $\mathrm{Pi}+\mathrm{MeAm}) .{ }^{* *}(\mathrm{p}<0.01)$, ${ }^{* * *}(\mathrm{p}<0.001)$ indicates statistically significant difference from control treated HAoSMCs; $\uparrow+\uparrow(p<0.001)$ indicates statistically significant difference from HAoSMCs treated with $3 \mathrm{mM}$ sodium phosphate alone.
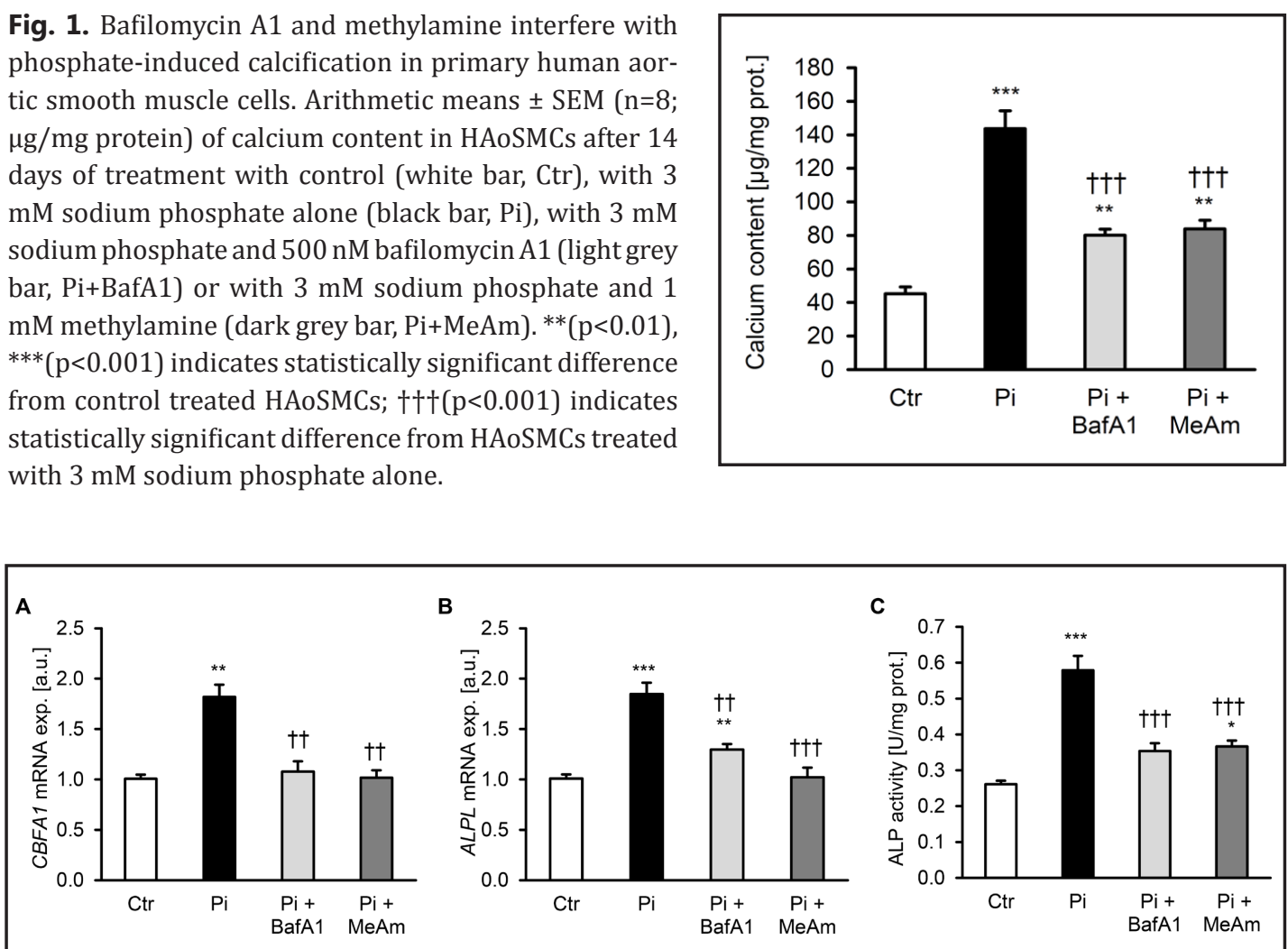

Fig. 2. Bafilomycin $A 1$ and methylamine inhibit phosphate-induced osteoinductive signaling in primary human aortic smooth muscle cells. Arithmetic means \pm SEM ( $\mathrm{n}=10$; arbitrary units, a.u.) of CBFA1 (A) and ALPL (B) relative mRNA expression in HAoSMCs after 24 hours of treatment with control (white bars, Ctr), with $2 \mathrm{mM} \beta$-glycerophosphate alone (black bars, Pi), with $2 \mathrm{mM} \beta$-glycerophosphate and $500 \mathrm{nM}$ bafilomycin A1 (light grey bars, Pi+BafA1) or with $2 \mathrm{mM} \beta$-glycerophosphate and $1 \mathrm{mM}$ methylamine (dark grey bars, $\mathrm{Pi}+\mathrm{MeAm})$. Arithmetic means $\pm \mathrm{SEM}(\mathrm{n}=4 ; \mathrm{U} / \mathrm{mg}$ protein) of alkaline phosphatase activity $(\mathrm{C})$ in HAoSMCs after 7 days of treatment with control (white bars, Ctr), with $2 \mathrm{mM} \beta$-glycerophosphate alone (black bars, Pi), with $2 \mathrm{mM} \beta$-glycerophosphate and $500 \mathrm{nM}$ bafilomycin A1 (light grey bars, Pi+BafA1) or with $2 \mathrm{mM} \beta$-glycerophosphate and $1 \mathrm{mM}$ methylamine (dark grey bars, Pi+MeAm). ${ }^{*}(\mathrm{p}<0.05),{ }^{* *}(\mathrm{p}<0.01),{ }^{* * *}(\mathrm{p}<0.001)$ indicates statistically significant difference from control treated HAoSMCs; $\uparrow+(\mathrm{p}<0.01),+\dagger+(\mathrm{p}<0.001)$ indicates statistically significant difference from HAoSMCs treated with $2 \mathrm{mM} \beta$-glycerophosphate alone.

A1 and with or without dissipation of the $\mathrm{pH}$ gradient across the vacuolar membrane with methylamine. In a first step, the calcium deposition in HAoSMCs was determined. As illustrated in Fig. 1, the calcium content of HAoSMCs increased significantly following 14 days of treatment with calcification media containing $3 \mathrm{mM}$ sodium phosphate. The effect on calcium deposition was significantly blunted in the presence of either bafilomycin A1 $(500 \mathrm{nM})$ or methylamine $(1 \mathrm{mM})$. Thus, alkalinisation of acidic intracellular compartments inhibits the phosphate-induced calcification of HAoSMCs.

A further series of experiments explored whether the effects of bafilomycin A1 and methylamine on calcium content were paralleled by corresponding effects on osteo-/chondrogenic signaling. To this end, the transcript levels of the osteogenic transcription factor CBFA1 (Core-binding factor $\alpha 1$, RUNX2) and of alkaline phosphatase (ALPL) were determined. As shown in Fig. 2, the CBFA1 and ALPL mRNA expression were significantly up-regulated following 24 hours treatment with $2 \mathrm{mM} \beta$-glycerophosphate as phosphate donor in HAoSMCs, 


\section{Kidney \\ Blood Pressure \\ Research}
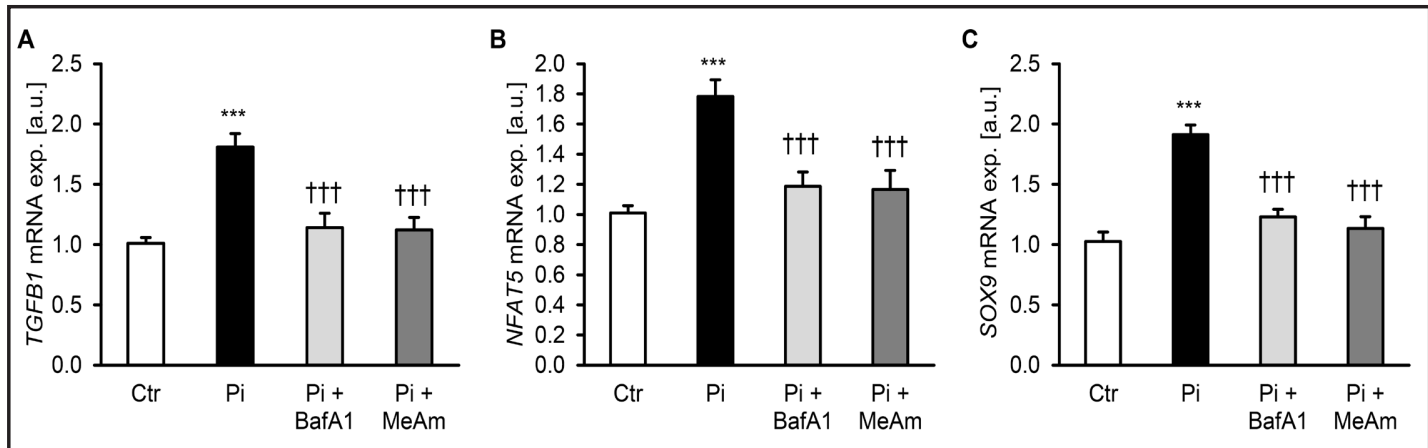

Fig. 3. Bafilomycin $A 1$ and methylamine interfere with phosphate-induced TGFß1 transcription and signaling in primary human aortic smooth muscle cells. Arithmetic means \pm SEM ( $n=10$; arbitrary units, a.u.) of TGFB1 (A), NFAT5 (B) and SOX9 (C) relative mRNA expression in HAoSMCs after 24 hours of treatment with control (white bars, Ctr), with $2 \mathrm{mM} \beta$-glycerophosphate alone (black bars, Pi), with $2 \mathrm{mM} \beta$-glycerophosphate and $500 \mathrm{nM}$ bafilomycin A1 (light grey bars, Pi+BafA1) or with $2 \mathrm{mM} \beta$-glycerophosphate and 1 $\mathrm{mM}$ methylamine (dark grey bars, $\mathrm{Pi}+\mathrm{MeAm}) .{ }^{* * *}(\mathrm{p}<0.001)$ indicates statistically significant difference from control treated HAoSMCs; $+\dagger+(\mathrm{p}<0.001)$ indicates statistically significant difference from HAoSMCs treated with $2 \mathrm{mM} \beta$-glycerophosphate alone.

an effect significantly blunted in the presence of either bafilomycin A1 or methylamine (Fig. 2A, B). Bafilomycin A1 and methylamine similarly interfered with the induction of alkaline phosphatase activity in HAoSMCs (Fig. 2C). Treatment for 7 days with $2 \mathrm{mM} \beta$-glycerophosphate increased significantly the alkaline phosphatase activity in HAoSMCs, an effect again significantly blunted following treatment with either bafilomycin A1 or methylamine. Taken together, bafilomycin A1 and methylamine inhibited osteo-/chondrogenic transformation of HAoSMCs and calcium depositions under high phosphate conditions.

A further series of experiments explored whether bafilomycin A1 and methylamine similarly impact on TGFß1 expression and signaling. Therefore, quantitative RT-PCR was employed to elucidate the effects on the transcript levels of TGFB1, TGFß1-sensitive transcription factor NFAT5 and NFAT5-downstream transcription factor SOX9. As illustrated in Fig. 3, the $\beta$-glycerophosphate-induced TGFB1, NFAT5 and SOX9 mRNA expression was significantly blunted and virtually abrogated by additional treatment with either bafilomycin A1 or methylamine in HAoSMCs.

Additional experiments addressed the role of TGFß1 on osteo-/chondrogenic signaling. As shown in Fig. 4, treatment for 24 hours of HAoSMCs with human TGFß1 protein mimicked the effects of $\beta$-glycerophosphate and significantly increased NFAT5, SOX9, CBFA1 and ALPL mRNA expression. No further significant increase of NFAT5, SOX9, CBFA1 and ALPL mRNA expression could be observed upon combined treatment of HAoSMCs with TGFß1 together with $\beta$-glycerophosphate (Fig. 4).

A final series of experiments explored whether the influence of high phosphate and of alkalinisation of acidic intracellular compartments on osteo-/chondrogenic signaling was secondary to their effects on TGFß1 by additional treatment of HAoSMCs with human TGFß1 protein. As a result, the transcript levels of NFAT5, SOX9, CBFA1 and ALPL were again significantly up-regulated following treatment with human TGFß1 protein in HAoSMCs (Fig. 5). Bafilomycin A1 again abrogated the $\beta$-glycerophosphate-induced NFAT5, SOX9, CBFA1 and ALPL mRNA expression. The effects of bafilomycin A1 on $\beta$-glycerophosphate-induced osteo-/chondrogenic signaling were completely reversed by the addition of human TGFß1 protein (Fig. 5). Thus, alkalinization of acidic cellular compartments inhibits the osteo-/ chondrogenic dedifferentiation of HAoSMCs at least partially by downregulation of TGFB1 and TGFß1-dependent signaling. 


\section{Kidney Blood Pressure Research}

Fig. 4. TGFß1 mimics the effect of phosphate on osteo-/chondrogenic signaling in primary human aortic smooth muscle cells. Arithmetic means \pm SEM ( $\mathrm{n}=4$; arbitrary units, a.u.) of NFAT5 (A), SOX9 (B), CBFA1 (C) and ALPL (D) relative mRNA expression in HAoSMCs after 24 hours of treatment with control (white bars, Ctr), with 10 ng/ml human TGFß1 alone (light grey bars, TGFß1), with $2 \mathrm{mM}$ $\beta$-glycerophosphate alone (black bars, Pi) or with $2 \mathrm{mM} \beta$-glycerophosphate and $10 \mathrm{ng} / \mathrm{ml}$ human TGFß1 (dark grey bars, $\mathrm{Pi}+\mathrm{TGF} ß 1) .{ }^{* * *}(\mathrm{p}<0.001)$ indicates statistically significant difference from control treated HAoSMCs.

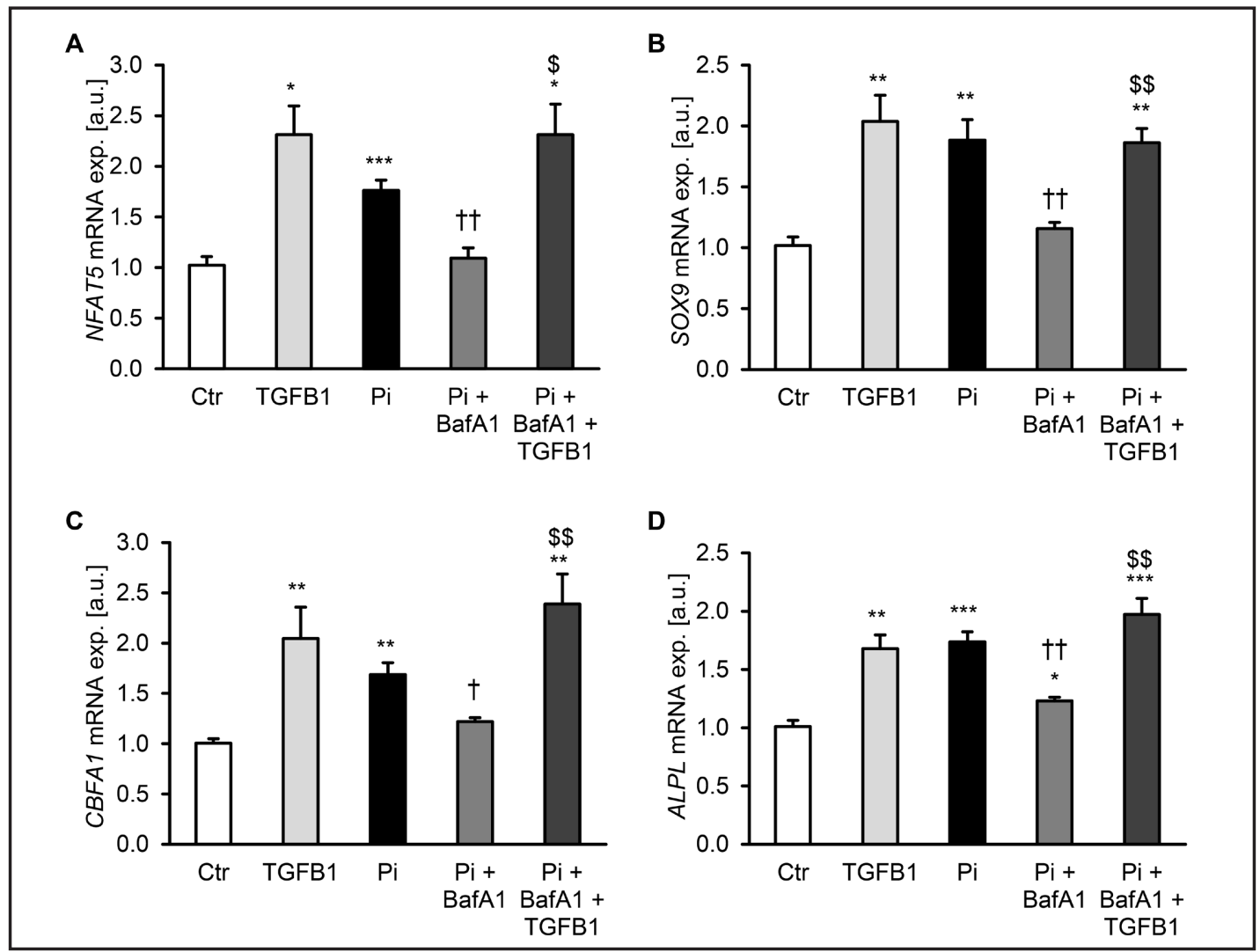

Fig. 5. TGFß1 reverses the effect of bafilomycin A1 on phosphate-induced osteo-/chondrogenic signaling in primary human aortic smooth muscle cells. Arithmetic means \pm SEM (n=8; arbitrary units, a.u.) of NFAT5
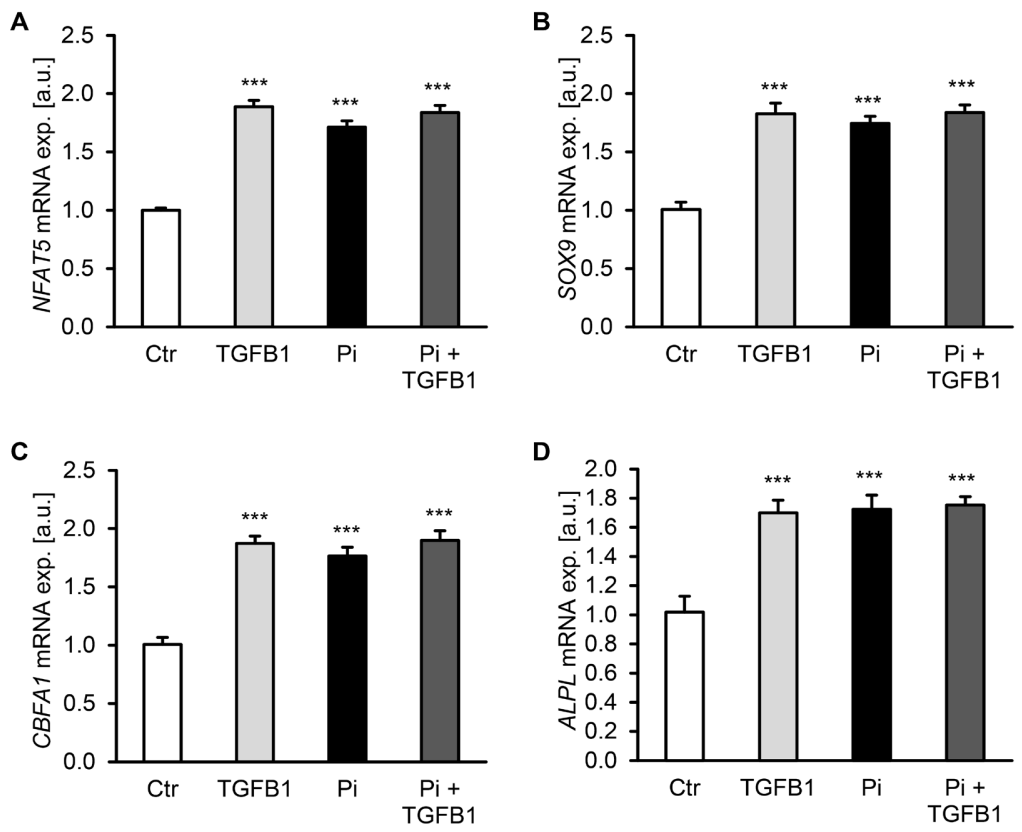


\section{Kidney Blood Pressure Research}

Kidney Blood Press Res 2015;40:490-499

DOI: 10.1159/000368524

Published online: September 30, 2015

(c) 2015 The Author(s). Published by S. Karger AG, Base www.karger.com/kb

Alesutan/Musculus/Castor/Alzoubi/Voelkl/Lang: Bafilomycin A1 and Methylamine-Sensitive VSMC Calcification

(A), SOX9 (B), CBFA1 (C) and ALPL (D) relative mRNA expression in HAoSMCs after 24 hours of treatment with control (white bars, Ctr), with $10 \mathrm{ng} / \mathrm{ml}$ human TGFß1 alone (light grey bars, TGFß1), with $2 \mathrm{mM}$ $\beta$-glycerophosphate alone (black bars, Pi), with $2 \mathrm{mM} \beta$-glycerophosphate and $500 \mathrm{nM}$ bafilomycin A1 (middle grey bars, Pi+BafA1) or with $2 \mathrm{mM} \beta$-glycerophosphate, $500 \mathrm{nM}$ bafilomycin A1 and $10 \mathrm{ng} / \mathrm{ml}$ human TGFß1 (dark grey bars, Pi+BafA1+TGFß1). ${ }^{*}(\mathrm{p}<0.05),{ }^{* *}(\mathrm{p}<0.01),{ }^{* * *}(\mathrm{p}<0.001)$ indicates statistically significant difference from control treated HAoSMCs; $\uparrow(\mathrm{p}<0.05), \dagger+(\mathrm{p}<0.01)$ indicates statistically significant difference from HAoSMCs treated with $2 \mathrm{mM} \beta$-glycerophosphate alone. $\$(\mathrm{p}<0.05), \$ \$(\mathrm{p}<0.01)$ indicates statistically significant difference between HAoSMCs treated with Pi+BafA1 and Pi+BafA1+TGFß1.

\section{Discussion}

The present study reveals that both, bafilomycin A1 and methylamine counteract osteoinductive signaling in primary human aortic smooth muscle cells (HAoSMCs) under high phosphate conditions. Treatment of HAoSMCs with high phosphate triggered osteo-/ chondrogenic reprogramming as reflected by up-regulation of osteogenic markers CBFA1 and ALPL, of TGFB1 and TGFß1-sensitive transcription factors NFAT5 and SOX9 expression, as well as alkaline phosphatase activity and calcium deposition. All those effects in HAoSMCs were ameliorated by both, bafilomycin A1 and methylamine. Methylamine and bafilomycin A1 are both known to interfere with lysosomal acidification [36-38]. Bafilomycin A1 may further decrease the cytoplasmic $\mathrm{pH}$, while methylamine rather increases cytoplasmic $\mathrm{pH}$ $[37,38]$. Thus alkalinization of acidic intracellular compartments rather than alterations of cytosolic pH may account for the inhibitory effects of bafilomycin A1 and methylamine on osteoinductive signaling.

Treatment of HAoSMCs with TGFß1 fully mimics the effect of high phosphate on the osteo-/chondrogenic signaling. The effects of phosphate and TGFß1 were not additive. The effect of phosphate with exogenously added TGFß1 on osteo-/condrogenic transformation was insensitive to bafilomycin A1. Alkalinization of acidic cellular compartments thus interferes with osteo-/chondrogenic signaling by affecting a mechanism upstream of TGFß1. Alkalinization of acidic cellular compartments may also prevent intracellular calcium overload and apoptosis of vascular smooth muscle cells (VSMCs) [39]. The present observations do not allow safe conclusions on the mechanisms involved in bafilomycin A1 and methylamine sensitivity of TGFß1 expression and function.

Alkalinization of acidic cellular compartments has previously been shown to impede the maturation of TGFß1, an effect presumably due to inhibition of $\mathrm{pH}$-sensitive luminal enzymes [30]. Impaired acidification of endosomes could further disrupt receptor/ligand dissociation and interfere with TGFß1 receptor externalization [40, 41]. How an alkalinization of the acidic cellular compartments affects the TGFB1 transcript levels, remains, however, elusive. TGFß1 is known to be up-regulated by excessive extracellular phosphate concentrations [42] and to stimulate cellular senescence thus contributing to aging and vascular osteoinduction [42]. Conversely, interference with TGFß1 signaling counteracts vascular calcification [43].

In view of previous [28] and present observations, alkalinization of acidic cellular compartments may be a novel therapeutic option in the prevention of vascular calcification. The treatment may be particularly important in patients with chronic kidney disease (CKD), which suffer from hyperphosphatemia and mineral bone disorder (MBD) [15, 44]. In CKD patients stimulation of osteo-/chondrogenic reprogramming [45] leads to vascular calcification, which in turn triggers cardiovascular events [46], the leading cause of death in those patients [47]. Osteo-/chondrogenic reprogramming and vascular calcification may affect further clinical conditions. NFAT5 is up-regulated by hyperglycaemia [48] and NFAT5-dependent osteo-/chondrogenic transformation of VSMCs may thus lead to vascular calcification in diabetes [49]. NFAT5 is further up-regulated and thus osteo-/chondrogenic reprogramming presumably fostered by dehydration [50], inflammation [50], hypoxia [51] and ischemia [51]. 


\section{Kidney \\ Blood Pressure Research}

Kidney Blood Press Res 2015;40:490-499

\begin{tabular}{l|l}
\hline DOI: 10.1159/000368524 & (C) 2015 The Author(s). Published by S. Karger AG, Basel
\end{tabular}

Published online: September 30, 2015 www.karger.com/kbr

VSMC Calcification

\section{Conclusions}

The present observations reveal that bafilomycin A1 and methylamine disrupt osteo-/ chondrogenic transformation and calcification of VSMCs and thus lend further support for the hypothesis that the $\mathrm{pH}$ of acidic cellular compartments plays a decisive role in osteoinductive signaling. The present observations further show that bafilomycin A1 does not reverse the activation of the osteoinductive signaling by TGFß1.

\section{Disclosure Statement}

The authors of this manuscript state that they do not have any conflict of interests and nothing to disclose.

\section{Acknowledgements}

Theauthorsacknowledge thetechnicalassistance of E. Faberand themeticulous preparation of the manuscript by T. Loch. The study was supported by the Deutsche Forschungsgemeinschaft (DFG 315/15-1) and the European Union Seventh Framework Programme (FP7/2007-2013) under grant agreement: 603288 .

\section{References}

1 Kapustin A, Shanahan CM: Targeting vascular calcification: softening-up a hard target. Curr Opin Pharmacol 2009;9:84-89.

2 Peacock M: Calcium metabolism in health and disease. Clin J Am Soc Nephrol 2010;5:S23-S30.

3 Weissen-Plenz G, Nitschke Y, Rutsch F: Mechanisms of arterial calcification: spotlight on the inhibitors. Adv Clin Chem 2008;46:263-293.

4 Shroff R, Long DA, Shanahan C: Mechanistic insights into vascular calcification in CKD. J Am Soc Nephrol 2013;24:179-189.

5 Giachelli CM: Vascular calcification: in vitro evidence for the role of inorganic phosphate. J Am Soc Nephrol 2003;14:S300-S304.

6 Tonelli M, Sacks F, Pfeffer M, Gao Z, Curhan G: Relation between serum phosphate level and cardiovascular event rate in people with coronary disease. Circulation 2005;112:2627-2633.

7 Staude H, Jeske S, Schmitz K, Warncke G, Fischer DC: Cardiovascular risk and mineral bone disorder in patients with chronic kidney disease. Kidney Blood Press Res 2013;37:68-83.

8 Mizobuchi M, Towler D, Slatopolsky E: Vascular calcification: the killer of patients with chronic kidney disease. J Am Soc Nephrol 2009;20:1453-1464.

9 Steitz SA, Speer MY, Curinga G, Yang HY, Haynes P, Aebersold R, Schinke T, Karsenty G, Giachelli CM: Smooth muscle cell phenotypic transition associated with calcification: upregulation of $\mathrm{Cbfa} 1$ and downregulation of smooth muscle lineage markers. Circ Res 2001;89:1147-1154.

10 Dalle Carbonare L, Innamorati G, Valenti MT: Transcription factor Runx2 and its application to bone tissue engineering. Stem Cell Rev 2012;8:891-897.

11 Moe SM, Chen NX: Pathophysiology of vascular calcification in chronic kidney disease. Circ Res 2004;95:560567.

12 Kuro-o M: Klotho, phosphate and FGF-23 in ageing and disturbed mineral metabolism. Nat Rev Nephrol 2013;9:650-660.

13 Lin ME, Chen T, Leaf EM, Speer MY, Giachelli CM: Runx2 Expression in Smooth Muscle Cells Is Required for Arterial Medial Calcification in Mice. Am J Pathol 2015;185:1958-1969. 


\section{Kidney \\ Blood Pressure Research}

Kidney Blood Press Res 2015;40:490-499

\begin{tabular}{l|l}
\hline DOI: 10.1159/000368524 & (C) 2015 The Author(s). Published by S. Karger AG, Basel
\end{tabular}

Published online: September 30, 2015 www.karger.com/kbr

14 Voelkl J, Alesutan I, Leibrock CB, Quintanilla-Martinez L, Kuhn V, Feger M, Mia S, Ahmed MS, Rosenblatt KP, Kuro-o M, Lang F: Spironolactone ameliorates PIT1-dependent vascular osteoinduction in klotho-hypomorphic mice. J Clin Invest 2013;123:812-822.

15 Hu MC, Shi M, Zhang J, Quinones H, Griffith C, Kuro-O M, Moe OW: Klotho deficiency causes vascular calcification in chronic kidney disease. J Am Soc Nephrol 2011;22:124-136.

16 Weng JJ, Su Y: Nuclear matrix-targeting of the osteogenic factor Runx2 is essential for its recognition and activation of the alkaline phosphatase gene. Biochim Biophys Acta 2013;1830:2839-2852.

17 Murshed M, McKee MD: Molecular determinants of extracellular matrix mineralization in bone and blood vessels. Curr Opin Nephrol Hypertens 2010;19:359-365.

18 Hiyama A, Gogate SS, Gajghate S, Mochida J, Shapiro IM, Risbud MV: BMP-2 and TGF-beta stimulate expression of beta1,3-glucuronosyl transferase 1 (GlcAT-1) in nucleus pulposus cells through AP1, TonEBP, and Sp1: role of MAPKs. J Bone Miner Res 2010;25:1179-1190.

19 Caron MM, van der Windt AE, Emans PJ, van Rhijn LW, Jahr H, Welting TJ: Osmolarity determines the in vitro chondrogenic differentiation capacity of progenitor cells via nuclear factor of activated T-cells 5 . Bone 2013;53:94-102.

20 Neven E, Persy V, Dauwe S, De Schutter T, De Broe ME, D'Haese PC: Chondrocyte rather than osteoblast conversion of vascular cells underlies medial calcification in uremic rats. Arterioscler Thromb Vasc Biol 2010;30:1741-1750.

21 Xu Z, Ji G, Shen J, Wang X, Zhou J, Li L: SOX9 and myocardin counteract each other in regulating vascular smooth muscle cell differentiation. Biochem Biophys Res Commun 2012;422:285-290.

22 Liu X, Bai C, Gong D, Yuan Y, Han L, Lu F, Han Q Tang H, Huang S, Xu Z: Pleiotropic effects of transforming growth factor-beta1 on pericardial interstitial cells. Implications for fibrosis and calcification in idiopathic constrictive pericarditis. J Am Coll Cardiol 2011;57:1634-1635.

23 Pai AS, Giachelli CM: Matrix remodeling in vascular calcification associated with chronic kidney disease. J Am Soc Nephrol 2010;21:1637-1640.

24 Tachi K, Takami M, Sato H, Mochizuki A, Zhao B, Miyamoto Y, Tsukasaki H, Inoue T, Shintani S, Koike T, Honda Y, Suzuki O, Baba K, Kamijo R: Enhancement of bone morphogenetic protein-2-induced ectopic bone formation by transforming growth factor-beta1. Tissue Eng Part A 2011;17:597-606.

25 Liu D, Cui W, Liu B, Hu H, Liu J, Xie R, Yang X, Gu G, Zhang J, Zheng H: Atorvastatin Protects Vascular Smooth Muscle Cells From TGF-beta1-Stimulated Calcification by Inducing Autophagy via Suppression of the betaCatenin Pathway. Cell Physiol Biochem 2014;33:129-141.

26 Mackenzie NC, MacRae VE: The role of cellular senescence during vascular calcification: a key paradigm in aging research. Curr Aging Sci 2011;4:128-136.

27 Wang JC, Bennett M: Aging and atherosclerosis: mechanisms, functional consequences, and potential therapeutics for cellular senescence. Circ Res 2012;111:245-259.

28 Leibrock CB, Alesutan I, Voelkl J, Pakladok T, Michael D, Schleicher E, Kamyabi-Moghaddam Z, QuintanillaMartinez L, Kuro-o M, Lang F: NH4Cl Treatment Prevents Tissue Calcification in Klotho Deficiency. J Am Soc Nephrol DOI: 2015;10.1681/ASN.2014030230

29 Ling H, Ardjomand P, Samvakas S, Simm A, Busch GL, Lang F, Sebekova K, Heidland A: Mesangial cell hypertrophy induced by $\mathrm{NH} 4 \mathrm{Cl}$ : role of depressed activities of cathepsins due to elevated lysosomal pH. Kidney Int 1998;53:1706-1712.

30 Basque J, Martel M, Leduc R, Cantin AM: Lysosomotropic drugs inhibit maturation of transforming growth factor-beta. Can J Physiol Pharmacol 2008;86:606-612.

31 Jara A, Felsenfeld AJ, Bover J, Kleeman CR: Chronic metabolic acidosis in azotemic rats on a high-phosphate diet halts the progression of renal disease. Kidney Int 2000;58:1023-1032.

32 Mendoza FJ, Lopez I, Montes dO, Perez J, Rodriguez M, Aguilera-Tejero E: Metabolic acidosis inhibits soft tissue calcification in uremic rats. Kidney Int 2008;73:407-414.

33 Jara A, Chacon C, Ibaceta M, Valdivieso A, Felsenfeld AJ: Effect of ammonium chloride and dietary phosphorus in the azotaemic rat. I. Renal function and biochemical changes. Nephrol Dial Transplant 2004;19:1986-1992.

34 Gagliardi S, Rees M, Farina C: Chemistry and structure activity relationships of bafilomycin A1, a potent and selective inhibitor of the vacuolar H+-ATPase. Curr Med Chem 1999;6:1197-1212.

35 Seglen PO, Grinde B, Solheim AE: Inhibition of the lysosomal pathway of protein degradation in isolated rat hepatocytes by ammonia, methylamine, chloroquine and leupeptin. Eur J Biochem 1979;95:215-225. 


\section{Kidney \\ Blood Pressure Research}

Kidney Blood Press Res 2015;40:490-499

\begin{tabular}{l|l}
\hline DOI: 10.1159/000368524 & (C) 2015 The Author(s). Published by S. Karger AG, Base
\end{tabular}

Published online: September 30, 2015 www.karger.com/kbr

36 Beers MF: Inhibition of cellular processing of surfactant protein $\mathrm{C}$ by drugs affecting intracellular pH gradients. J Biol Chem 1996;271:14361-14370.

37 Heming TA, Traber DL, Hinder F, Bidani A: Effects of bafilomycin A1 on cytosolic pH of sheep alveolar and peritoneal macrophages: evaluation of the $\mathrm{pH}$-regulatory role of plasma membrane V-ATPases. J Exp Biol 1995;198:1711-1715.

38 Sweatt JD, Connolly TM, Cragoe EJ, Limbird LE: Evidence that Na+/H+ exchange regulates receptor-mediated phospholipase A2 activation in human platelets. J Biol Chem 1986;261:8667-8673.

39 Ewence AE, Bootman M, Roderick HL, Skepper JN, McCarthy G, Epple M, Neumann M, Shanahan CM, Proudfoot D: Calcium phosphate crystals induce cell death in human vascular smooth muscle cells: a potential mechanism in atherosclerotic plaque destabilization. Circ Res 2008;103:e28-34.

40 Balogh P, Katz S, Kiss AL: The role of endocytic pathways in TGF-beta signaling. Pathol Oncol Res 2013;19:141148.

41 Johnson LS, Dunn KW, Pytowski B, McGraw TE: Endosome acidification and receptor trafficking: bafilomycin A1 slows receptor externalization by a mechanism involving the receptor's internalization motif. Mol Biol Cell 1993;4:1251-1266.

42 Wang N, Wang X, Xing C, Sun B, Yu X, Hu J, Liu J, Zeng M, Xiong M, Zhou S, Yang J: Role of TGF-beta1 in bone matrix production in vascular smooth muscle cells induced by a high-phosphate environment. Nephron Exp Nephrol 2010;115:e60-e68.

43 Kanno Y, Into T, Lowenstein CJ, Matsushita K: Nitric oxide regulates vascular calcification by interfering with TGF- signalling. Cardiovasc Res 2008;77:221-230.

44 Moe SM, Drueke T, Lameire N, Eknoyan G: Chronic kidney disease-mineral-bone disorder: a new paradigm. Adv Chronic Kidney Dis 2007;14:3-12.

45 Koleganova N, Piecha G, Ritz E, Schirmacher P, Muller A, Meyer HP, Gross ML: Arterial calcification in patients with chronic kidney disease. Nephrol Dial Transplant 2009;24:2488-2496.

46 London GM, Guerin AP, Marchais SJ, Metivier F, Pannier B, Adda H: Arterial media calcification in end-stage renal disease: impact on all-cause and cardiovascular mortality. Nephrol Dial Transplant 2003;18:1731-1740.

47 Foley RN, Parfrey PS, Sarnak MJ: Epidemiology of cardiovascular disease in chronic renal disease. J Am Soc Nephrol 1998;9:S16-S23.

48 Hernandez-Ochoa EO, Robison P, Contreras M, Shen T, Zhao Z, Schneider MF: Elevated extracellular glucose and uncontrolled type 1 diabetes enhance NFAT5 signaling and disrupt the transverse tubular network in mouse skeletal muscle. Exp Biol Med (Maywood) 2012;237:1068-1083.

49 Snell-Bergeon JK, Budoff MJ, Hokanson JE: Vascular calcification in diabetes: mechanisms and implications. Curr Diab Rep 2013;13:391-402.

50 Neuhofer W: Role of NFAT5 in inflammatory disorders associated with osmotic stress. Curr Genomics 2010;11:584-590.

51 Villanueva S, Suazo C, Santapau D, Perez F, Quiroz M, Carreno JE, Illanes S, Lavandero S, Michea L, Irarrazabal CE: NFAT5 is activated by hypoxia: role in ischemia and reperfusion in the rat kidney. PLoS One 2012;7:e39665. 